\title{
Shifting care from community hospitals to intensive community support: a mixed method study
}

\author{
Kate S. Williams ${ }^{1}$, Stoyan Kurtev ${ }^{2}$, Kay Phelps ${ }^{3}$, Emma Regen ${ }^{3}$, Simon Conroy $^{4}$ and Andrew Wilson ${ }^{5}$ \\ ${ }^{1}$ Senior Research Fellow in Nursing, Department of Health Sciences, University of Leicester, Leicester, UK \\ ${ }^{2}$ Information Analyst, Department of Health Sciences, University of Leicester, Leicester, UK \\ ${ }^{3}$ Research Fellow, Department of Health Sciences, University of Leicester, Leicester, UK \\ ${ }^{4}$ Professor of Geriatric Medicine, Department of Health Sciences, University of Leicester, Leicester, UK \\ ${ }^{5}$ Professor of Primary Care Research, Department of Health Sciences, University of Leicester, Leicester, UK
}

\begin{abstract}
Aim: To examine how the introduction of intensive community support (ICS) affected admissions to community hospital $(\mathrm{CH})$ and to explore the views of patients, carers and health professionals on this transition. Background: ICS was introduced to provide an alternative to $\mathrm{CH}$ provision for patients (mostly very elderly) requiring general rehabilitation. Method: Routine data from both services were analysed to identify the number of admissions and length of stay between September 2012 and September 2014. In total, 10 patients took part in qualitative interviews. Qualitative interviews and focus groups were undertaken with 19 staff members, including managers and clinicians. Findings: There were 5653 admissions to $\mathrm{CH}$ and 1710 to ICS between September 2012 and September 2014. In the five months before the introduction of ICS, admission rates to $\mathrm{CH}$ were on average 217/month; in the final five months of the study, when both services were fully operational, average numbers of patients admitted were: $\mathrm{CH} 162$ (a 25\% reduction), ICS 97, total 259 (a 19\% increase). Patients and carers rated both ICS and CH favourably compared with acute hospital care. Those who had experienced both services felt each to be appropriate at the time; they appreciated the $24 \mathrm{~h}$ availability of staff in $\mathrm{CH}$ when they were more dependent, and the convenience of being at home after they had improved. In general, staff welcomed the introduction of ICS and appreciated the advantages of homebased rehabilitation. Managers had a clearer vision of ICS than staff on the ground, some of whom felt underprepared to work in the community. There was a consensus that ICS was managing less complex and dependent patients than had been envisaged. Conclusion: ICS can provide a feasible adjunct to $\mathrm{CH}$ that is acceptable to patients. More work is needed to promote the vision of ICS amongst staff in both community and acute sectors.
\end{abstract}

Key words: community hospital; intermediate care services; mixed methods; older people; rehabilitation

Received 27 October 2016; revised 22 March 2017; accepted 17 August 2017; first published online 13 September 2017

\section{Introduction}

There is growing evidence that alternatives to acute hospital admission, especially for older

Correspondence to: Andrew Wilson, Department of Health Sciences, Centre for Medicine, University of Leicester, Leicester LE1 7RH, UK. Email: aw7@le.ac.uk

(C) Cambridge University Press 2017 people, can deliver comparable or better clinical outcomes, with higher satisfaction and potentially lower costs (Conley et al., 2016). In the United Kingdom, the National Audit Office concluded that: 'Many emergency admissions to hospital are avoidable and many patients stay in hospital longer than is necessary' (National Audit Office, 2013). In response, intermediate care services have 
been established to avoid admission or enable early discharge. Local commissioners have had discretion over which specific services to support and develop, for example whether to invest in community hospitals $(\mathrm{CH})$ or home-based intermediate care, such as intensive community support (ICS). However there is limited evidence to guide commissioners on which form of intermediate care is most effective, and so decisions appear often to be made on the basis of local history, tradition and availability of estates, including CHs. The 2014 national audit of intermediate care reported mean budgets for home-based and bed-based intermediate care were $£ 0.8 \mathrm{M}$ and $£ 1.2 \mathrm{M}$, respectively, per 10000 weighted population, with little change from the previous year. Average costs per episode of care were $£ 1045$ for home-based services and $£ 5549$ for bed-based services (NHS Benchmarking Network, 2014).

A narrative review of $\mathrm{CH}$ found very little evaluative work on effectiveness and efficiency (Heaney et al., 2006). Studies have shown that they tend to be used as an additional service rather than an alternative to acute hospital (Cook and Porter, 1998) and this is supported by a recent national benchmarking report which found no association between $\mathrm{CH}$ provision and acute bed use (NHS Benchmarking Network, 2013). However length of stay (LOS) in acute hospital was marginally less where $\mathrm{CH}$ provision was greater, suggesting $\mathrm{CH}$ is used as a step-down facility. The overall finding was wide variation both in volume and type of $\mathrm{CH}$. The only trial of rehabilitation in $\mathrm{CH}$ found greater independence was achieved in this setting compared with rehabilitation in acute hospitals, with similar cost effectiveness (Young et al., 2007; O'Reilly et al., 2008).

There is stronger evidence that home-based care can be effective. A Cochrane review concluded that admission avoidance hospital at home (HAH) produced similar clinical outcomes to acute hospital care and higher levels of patient satisfaction, at broadly similar cost (Shepperd et al., 2008; 2009a). A review comparing early discharge $\mathrm{HAH}$ with continued admission found similar costs and outcomes, but that people admitted to HAH were more satisfied and, amongst older people and stroke patients, less likely to be discharged to residential care (Shepperd et al., 2009b).

In summary, evidence supports the development of services to provide alternatives to acute hospital admissions, but it is less clear what form or Primary Health Care Research \& Development 2018; 19: 53-63 forms these should take, and specifically there have been no studies examining the relationship between $\mathrm{CH}$ and home-based intermediate care.

\section{Local setting}

Local health provision includes a large acute hospital with emergency department facilities in the city, with a network of CHs provided by the Community Trust in eight locations across the county. The changes evaluated in this paper comprised the introduction of ICS, reduction in $\mathrm{CH}$ capacity and a shift to Advanced Nurse Practitioner led care, supported by 'interface geriatricians', in both settings. ICS was designed as an alternative to $\mathrm{CH}$ for those with more intensive needs than could be provided by existing community services. It was anticipated that most rehabilitation patients previously managed in $\mathrm{CH}$ would be managed in ICS, with the exception of those needing $24 \mathrm{~h}$ care. It provides a package of care delivered by generic workers, therapists, dieticians, long-term condition specialists and social care, with a projected average LOS of 20 days. Both services were designed to serve a predominantly older population.

The purpose of the current study was to examine the impact of introducing the ICS service. Specifically, to assess how the introduction of ICS affected admissions to $\mathrm{CH}$, to examine how the two services interacted and to explore the views of patients, carers, health professionals and other stakeholders on both services.

\section{Methods}

Routine data provided by the Community Trust were analysed for $\mathrm{CH}$ from April 2012 and for ICS from its introduction in September 2012 to September 2014. These data included information on age and sex of patients and source of admission, LOS and discharge destination.

Data from $\mathrm{CH}$ included information on the date of admission, type (emergency, planned or other), source (eg, home, hospital), age, diagnosis, LOS and discharge destination. Data from ICS were collected from SystmOne, an electronic record used in primary care. This included referral date, source of admission, referral source and in urgency, reason for referral (in free text) and LOS. Data on age and gender were requested but was not obtained. Clinical data, for example diagnoses 
and severity, were not collected in a retrievable form for ICS patients.

Number of admissions and average LOS for both services were calculated monthly during the study period. Referral source and discharge destinations were compared for the total study period.

The qualitative component of the study (conducted in 2014) comprised semi-structured interviews with patients who had received care in $\mathrm{CH}$ or ICS and interviews and focus groups with stakeholders of the service, including service providers and managers. Topic guides (available from the authors) were developed for both. The focus groups covered three geographical locations and the numbers of interviewees was balanced across $\mathrm{CH}$ and ICS. Participants were identified purposively, in order to ensure the inclusion of different professional groups and grades of staff. Patients were recruited by clinical staff at the time of admission and written consent was obtained before the interview.

Interviews were analysed by K.P. and E.R. using the framework approach (Gale et al., 2013). Emerging themes from both the staff and patient interviews were used to generate a coding framework which was subsequently used to code the interview transcripts thus enabling further development and modification of the key themes. Patterns, associations, concepts and explanations in the data were identified via a process of mapping and interpretation. Analysis was facilitated by the use of NVivo 10 (Castleberry, 2014). Themes generated during analysis were regularly discussed and validated by several members of the research team.

\section{Ethical approval}

Ethics permission was obtained on 02 December 2013 from NRES Committee North West - Haydock (reference 13/NW/0760).

\section{Results}

\section{Patient population}

In total, there were 5653 patients admitted to $\mathrm{CH}$ and 1710 to $\mathrm{CH}$. As shown in Table 1, the main source of admission to $\mathrm{CH}$ was the acute hospital $(88 \%)$, with a relatively small number of patients admitted from their home, including some who transferred from ICS. In contrast, most (64\%) admissions to ICS were from home, with most of the remainder admitted from $\mathrm{CH}$.

Figure 1 shows time trends for the total number of patients admitted to both services, admissions to each service and the number of transfers from ICS to $\mathrm{CH}$. In the five months before ICS was started, the average number of patients admitted per month to $\mathrm{CH}$ was 217 . In the final five months when both services were fully operational, average numbers of patients admitted were: $\mathrm{CH} 162$ (a $25 \%$ reduction), ICS 97, total 259 (a 19\% increase).

\section{Length of Stay (LOS)}

Average LOSs were calculated for patients who were admitted to and discharged from ICS or $\mathrm{CH}$, as shown in Figure 2. Mean LOS was 20.0 days for ICS and 25.8 days for $\mathrm{CH}$, and both decreased during the study period.

\section{Discharge}

Table 2 shows discharge destinations for $\mathrm{CH}$ and ICS. A higher proportion of patients from ICS were discharged home (79 versus 61\%) and a lower proportion was admitted to an acute hospital (15 versus 30\%). Deaths during admission were less in ICS (2\% or less compared with $5 \%$ in $\mathrm{CH}$ ).

Table 1 Sources of admission for community hospital $(\mathrm{CH})$ and intensive community support (ICS) patients

\begin{tabular}{lrrlrr}
\hline CH - source & $n$ & $\%$ & ICS - source & $n$ & $\%$ \\
\hline Home & 596 & 10 & Home & 1088 & 64 \\
Home (ICS) & 46 & 1 & CH & 413 & 24 \\
Acute Hospital (including ED) & 4971 & 88 & Acute Hospital & 19 & 1 \\
Care home & 40 & 1 & Care home & 10 & 1 \\
& & & No information & 180 & 10 \\
Total & 5653 & 100 & Total & 1710 & 100 \\
\hline
\end{tabular}

ED = emergency department. 


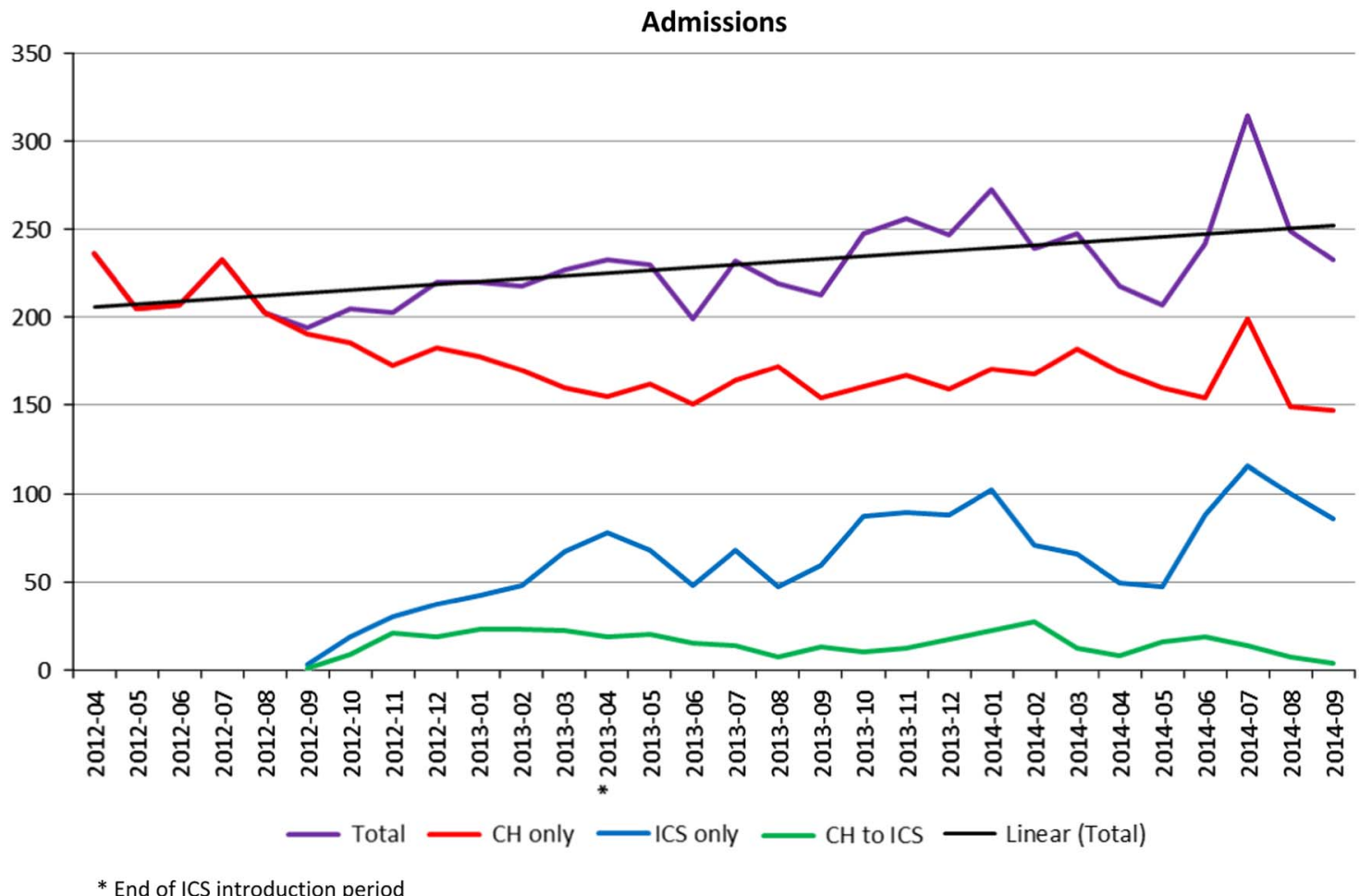

Figure 1 Time trends for admissions to community hospital (CH) and intensive community support (ICS). *End of ICS introduction period

\section{Qualitative findings}

Patient interviews

We had planned to interview a purposive sample of patients, but as fewer patients than expected were recruited, all who consented and were able to be contacted were interviewed $(n=10)$.

Four interviews were with patients who had received care in $\mathrm{CH}$ and six were with patients who had received ICS, three of whom had also received care in $\mathrm{CH}$ immediately before receiving ICS. All interviews took place three to six months following discharge from $\mathrm{CH}$ or ICS.

Of the four patients who received care in a $\mathrm{CH}$, three were female (aged 82, 90 and 91 years) and one was male (aged 78 years). LOS ranged from two to five weeks. All four returned home following their admission. Of the six patients who received ICS, five were female [aged 34, $74(\times 3)$ and 80 years] and one was male (aged 75 years). LOS of participants ranged from two to five weeks. Familiarisation with the transcripts identified the

Primary Health Care Research \& Development 2018; 19: 53-63 following themes: choice and information, positive and negative views of each service and preferred place of care.

$\mathrm{CH}$ : patients' views and experiences

Choice and information

All participants were transferred to $\mathrm{CH}$ from acute care for rehabilitation. Most reported they were happy with the decision to transfer to $\mathrm{CH}$ but some were not asked where they wanted to go and had little choice about location, which was determined by bed availability.

'They didn't ask me, they just said that they were going to send me to a rehabilitation hospital and it was CH1'.

'No. I mean I just kept saying CH2's where I would like to go. I would have gone to $\mathrm{CH} 4$ or CH1. I would not have gone to CH5 or CH6 because that defeated the objective of trying to get you nearer to your home and 


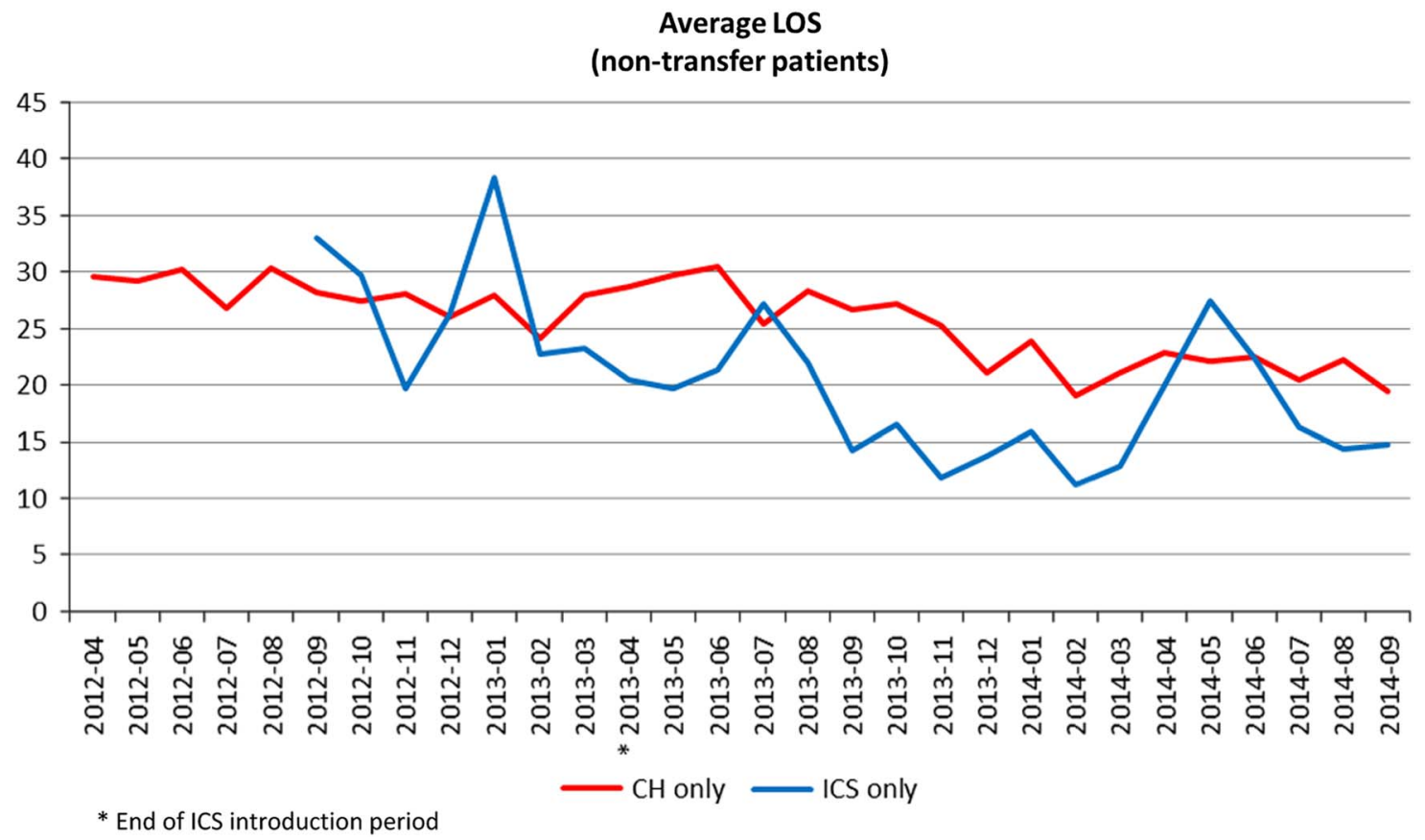

Figure 2 Average length of stay (LOS) for community hospital (CH) and intensive community support (ICS), excluding patents transferred from $\mathrm{CH}$ to ICS. *End of ICS introduction period

Table 2 Discharge destination for community hospital $(\mathrm{CH})$ and intensive community support (ICS) patients

\begin{tabular}{|c|c|c|c|c|c|}
\hline $\mathrm{CH}$ - destination & & $\%$ & ICS - destination & & $\%$ \\
\hline Home & 3035 & 54 & Home & 1351 & 79 \\
\hline Home (ICS) & 413 & 7 & & & \\
\hline Acute Hospital & 1696 & 30 & Acute hospital & 256 & 15 \\
\hline Care home & 170 & 3 & Community hospital & 51 & 3 \\
\hline Died & 282 & 5 & Care home & 14 & 1 \\
\hline Not known & 57 & 1 & Not known (including deaths) & 38 & 2 \\
\hline Total & 5653 & 100 & Total & 1710 & 100 \\
\hline
\end{tabular}

family. I mean what's the point? I can't see a point of that one at all'.

\section{Positives}

Most patients were complimentary about the care they received in $\mathrm{CH}$, in particular the caring attitude and competence of the nurses. The environment and more personalised care in $\mathrm{CH}$ were compared favourably with care in acute hospital settings.

'but I think with it (acute hospital) being a bigger institution, bigger set up there, I think
I didn't feel quite as individual, I found I had more individuality at $\mathrm{CH} 4$. I liked the scale of the place. It was much more friendly and intimate'.

Negatives

Staff were felt not always to be responsive to patients' requests for assistance, particularly with regard to toileting and at night.

'The worst bits were the night shifts.. you'd ask a nurse, they'd always say "oh see you in a

Primary Health Care Research \& Development 2018; 19: 53-63 
minute" and never did, made me angry at first, I got used to it in the end'.

Preferred place of care

Patients strongly identified $\mathrm{CH}$ as their preferred place of care. Those patients who received $\mathrm{CH}$ care followed by ICS felt that they had needed $\mathrm{CH}$ care and could not have gone straight home with ICS from acute hospital. The safe environment, with staff always present to deal with any problems, was identified as a key benefit. This was contrasted with the potential for isolation at home where care was delivered in intermittent visits.

'I think it [CH] probably did [help], because you haven't got to worry about anything. I mean, if I'd have been at home, I would have been on my own quite a bit of the time, however much help I'd got. I'd have been there and I think I would have been a bit worried. I felt safe in hospital'.

'It would have been a lot easier to be in CH1 than be at home, because if I needed medical attention I'd got it immediately there'.

ICS: patients' views and experiences

\section{Choice and information}

The degree of choice and information provided about ICS appeared to be mixed. One patient was simply told that she was being referred to ICS, primarily for physiotherapy, without much information or choice:

'They just referred me and that was it. Yeah, I didn't know. They just said the physio would be coming out to me'.

More positively, another patient, who received ICS following a stay in $\mathrm{CH}$, felt that she was given appropriate information about ICS:

'Well yes, I mean cos I said to [name], OK, what's ICS? I mean obviously, and I said it, cos she said "Oh you'll have a community nurse". I said "What, a district nurse?" "No" she said "They're different, they're in the ICS team"”.

Primary Health Care Research \& Development 2018; 19: 53-63
Positives

Most patients commented on the professionalism and caring attitude of the nurses who visited them at home while they received the service. As a result of the standard and quality of nursing care, patients felt safe and secure receiving their care in a community setting. There was appreciation of regular contacts and flexibility in response to need. The speed with which equipment, aids and adaptations were put in place at home was highlighted as a positive aspect of the service.

'Well it was as if to say "we're here, should you need us, let us know”, so it was almost like you have this service and we're happy to come and do whatever it is that we can to help you out'

'They put fantastic things in. Yeah. I mean they did all the, that was put through to them and they did exactly what the OT had told them to do...'

Some patients had expected more contact from their GPs, but appreciated that when ICS had identified the need for GP involvement this was arranged promptly.

'They got one of the doctors to come who I'd never seen before but she came and decided that she wasn't terribly happy with the look of it, the next day I was whizzed off to Acute Hospital 1 for a scan'.

Negatives

Some patients reported delays in the ICS service starting, ranging from one to several days. Problems with the physiotherapy component of ICS were also highlighted by some patients. The service was not as 'intensive' as expected with visits not occurring as frequently as anticipated or delivered by physiotherapy assistants rather than fully qualified staff. Delays in responding to requests for support were also reported.

'I think they (ICS) didn't come out for the first day or two, which surprised me. I had a feeling that - I thought there'd be somebody there the next day'. 
'Well it (physiotherapy) wasn't intensive by my standards, like it was -, they were very nice, very charming, very everything, but I don't think we had more than once, or one and a half times'.

Preferred place of care

Patients who had received care in $\mathrm{CH}$ before receiving ICS had valued the $\mathrm{CH}$ phase of their rehabilitation and felt that they could not have gone straight home with ICS from acute hospital.

Patients who were 'stepped up' to ICS spoke firmly in favour of this as their preferred place of care. The convenience of receiving care at home, being able to remain amongst family and friends and avoiding admission to hospital were identified as the main benefits of ICS.

'In fact [name of nurse] did say to me "you could come into hospital" but of course that would be even more intrusive than if I had the ladies coming in'.

\section{Staff interviews}

In total, 19 members of staff were interviewed alone or in small focus groups. Three senior staff (clinical and managerial) were interviewed singly, including the most relevant top-level managers responsible for the two services. In addition nurses and therapists from ICS and $\mathrm{CH}$ took part in a series of three focus groups, each with five or six participants. Unfortunately, despite several approaches, it was not possible to secure interviews with commissioners of the service or with any GPs as originally intended. Familiarisation with the transcripts identified the following themes: benefits/advantages and challenges/ disadvantages of each service.

\section{Benefits and advantages of $\mathrm{CH}$ care}

The perceived benefits of $\mathrm{CH}$ care included patient safety and confidence due to $24 \mathrm{~h}$ support. Therapy input, equipment and outcomes were felt to be superior due to the time therapists could spend with patients in a safe environment with a level of equipment that could not be provided at home.

'In hospital you've got more staff available, so if you've got somebody that needs two or three staff to keep them safe while you're practising mobility or transfers it's easier to do than in the community because you've got things like parallel bars'.

(FG1F5)

Patient management led by advanced nurse practitioners (ANPs) was welcomed by $\mathrm{CH}$ staff and was felt to have improved the quality of care, enabling care of more complex patients and reduced LOS. ANP's had access to advice from geriatricians when required, which gave them confidence to keep patients in $\mathrm{CH}$ when they may previously have been admitted to an acute hospital.

'Fantastic, they've (ANPs) reduced incidents, compliance for anti-microbial prescribing is enhanced - all sorts of things and our standards of nursing care on the wards has improved because the ANPs are canulating, drips are going up where they wouldn't before they would have been transferred back to the Acute. So the ANPs are very, very good, equivalent to registrars'.

\section{Challenges and disadvantages for $\mathrm{CH}$ care}

The challenges and disadvantages in $\mathrm{CH}$ brought about by the changes to the system of care included staff unhappiness at the closure of $\mathrm{CH}$ wards, leaving a feeling of vulnerability. Though staff valued the ANP's, some reported feeling 'out of their depth' and inadequately trained to deal with the higher level of nursing care required by more complex patients being cared for on the wards. It was felt that ANP's were performing the role or ward managers rather than clinical leads, and that the support from geriatricians was not adequate.

'But I think overall because of the higher dependency in the more ill patients that we've got, ... I would definitely prefer to see three trained staff on in the morning, if not evening as well'.

(FG3F3)

'If somebody's been acutely unwell or whatever, it's been a 999 ambulance or it's been phoning the geriatrician directly and saying "I've got this patient with these signs and symptoms, what would you like me to do?". I've never been able to arrange a visit'.

(FG2F3)

Primary Health Care Research \& Development 2018; 19: 53-63 


\section{Benefits and advantages of ICS}

The perceived benefits of the ICS service were that patients could go home from both acute and $\mathrm{CH}$ sooner than was previously the case. It was felt that most patients prefer to be at home and their relatives find it easier to visit patients at home than in hospital. There was a view that recovery and rehabilitation was better and faster in a patients usual environment, and that patient outcomes were improved by the ICS service. It was felt that the increased community therapy input had led to a higher level of support for patients at home, improved care in the community overall and increased the capacity of the community services.

'We get people that would otherwise have been in institutional/hospital settings into their own homes sooner, hopefully healthier, and that they do more for themselves in their own homes and therefore recover quicker...'

'We get patients out of hospital sooner and provide the therapy and the nursing that they would get in hospital but at home. So it releases the beds earlier'.

(FG1F3)

ANP management and the ICS service being embedded into existing service teams was felt to have improved continuity of care for patients who could be followed through their journey of care by the same staff. ICS was felt to have reduced admissions and readmissions to hospital, and facilitated early hospital discharge thus reducing LOS in hospital for individuals. ICS and ANP management was thought to have reduced pressure on GP's and changed CH staff attitudes about who could be cared for in their own homes. The creation of the ICS service and the moving of staff from closing $\mathrm{CH}$ wards to community teams meant that there were no enforced staff redundancies when services were reorganised. Finally care at home was thought to be cheaper than $\mathrm{CH}$ care, thus the ICS service was perceived to be saving money for the Community Trust.

'So the structure of the service, as it was originally conceived, was such that it should have been able to receive slightly sicker patients than your average intermediate care service. So we had, you know, not just Primary Health Care Research \& Development 2018; 19: 53-63 intermediate care nurses; we had ANPs, who are - a different breed. And we had the agreement and support from geriatricians to provide that high level of supervision'.

'When I've discharged patients from the $(\mathrm{CH})$ ward it's meant that I've been able to follow people up at home. And I have done it and it's nice, because you've seen them in the ward and you say "I'll see you when you're at home" and then you go out and see them at home'

(FG2F3)

'When we re-provided the (ICS) service we were able to identify some efficiencies that came from that. That wasn't the driver for doing this, but there was a reduction in because you don't have the infrastructure of the hospital overheads and so on'.

Challenges and disadvantages of ICS

Some staff believed that the ICS service was not providing an equivalent level of support for patients to that provided in $\mathrm{CH}$. There was a view that lower levels of therapy input, lack of equipment, and poor rehabilitative environment at home were not adequate to enable patients to achieve their full potential and maximise their outcomes. It was also felt that there was inadequate access to specialist services such as speech and language therapists and dieticians in the community.

'Because we are more a sort of general service - we haven't got the specialist skills necessarily

to do whatever they want like in hospital'.

(FG1F1)

'Yeah - I can't see many benefits to the patients other than they're at home. Because as we've said the care and attention that they get is obviously limited when they're at home'.

(FG3F5)

CH staff, including ANP's, felt reluctant to send patients home with ICS when they perceived them to require a high level of assistance, perhaps unconvinced that patients would be safe without someone on hand $24 \mathrm{~h}$ a day. They also felt that the additional administration in trying to get a patient 
home with ICS and the additional care they would need was prohibitively time consuming for complex patients.

'So whereas we would be treating people in the gym more, now patients aren't brought down to our gym as much as they're treated on the ward, because of all the telephone calls, all the paperwork that needs to go alongside in facilitating that discharge'.

(FG3F4)

The outcome of this was that the patients being cared for by the ICS service were less complex and less dependent than was originally envisaged.

'if we had proper ICS patients then I think we would struggle to really rehab them at a good enough level'

(FG1F4)

'So it may be that our intention of taking a population out of community hospitals and putting them into ICS has been achieved, but not with the cohort that we originally intended'.

There was thought to be a very wide interpretation of the eligibility criteria for the ICS service leading to confusion about who was appropriate for the service, and $\mathrm{CH}$ staff felt that this was inconsistently applied.

'I think we get anyone - we're always saying "they've got to be safe overnight" but that could be for anybody - it could be Social Services, the care call or nursing'.

(FG1F2)

'I think the criteria for referring patients [to ICS] seems to change sort of every other week'.

(FG3F4)

The fact that ICS was provided by the same staff that provided other community services meant that some staff were reallocated during high level of need or staff sickness. The number of services provided in the community and locality dependent referral systems was perceived to make access to community services confusing and inconsistent.
'I think the difficulty is that we have the ICS, ICT, Heart, Community Therapy, Community Nursing - what used to be Rapid Response or whatever - so the GPs or some hospitals will just refer into (intermediate care)'

(FG1F5)

The ANP's, though highly valued in $\mathrm{CH}$, were perceived as not providing sufficient support for ICS patients, perhaps because of lack of experience in working in the community. ICS staff spoke of their frustration at not being able to access ANP support and having to revert to GP support.

'You know they need certain help, you can then contact $(A N P)$ who then says too busy, phone the GP. After you're told that so many times, you think oh forget them. I'm going to the GP, my time is just as precious as yours'.

(FG2F5)

'Some of the ANPs we've recruited don't have a natural affinity for working in the Community and have struggled with having to visit people in their home. And I think some of them if you spoke to them would be honest and say "I don't like the ICS element of my job because I liked being on the ward"'.

The way the $\mathrm{CH}$ wards were closed and the ICS service introduced led to some staff resentment and dissatisfaction. Some $\mathrm{CH}$ staff who were moved to community teams did not feel consulted, and did not feel that they had a choice in their new roles. They felt there had been inadequate training and support in recognition that community work was very different to work on in-patient wards.

'It's very different going to see somebody in a hospital ward to going to seeing somebody out in their own home when there's only you there...It's about pulling on different resources as well, knowing what resources that you can pull on in the community'.

(FG2F2)

'They needed more staff then in the (community) and if you were willing to do that then you could do that. You had your interviews, most people got what they wanted. It's a case of if you want a job then that's where you are going. When all the wards closed down there

Primary Health Care Research \& Development 2018; 19: 53-63 
was, from the hierarchy, there was absolutely no support whatsoever. Staff morale was dire'.

(FG2F5)

\section{Discussion}

\section{Main conclusions}

The study has shown that an intensive, homebased service is consistent with a reduction of $\mathrm{CH}$ provision, in this case by $25 \%$. There is a risk that a service designed to be a substitute may increase demand and so provide additional rather than alternative provision. The finding that total admissions to both services increased after ICS was introduced raises this possibility, although there are several other potential explanations, including increases in the number of older people and the introduction of ANPs to $\mathrm{CH}$, which may have led to patients being admitted who would previously received care in an acute hospital. It should also be noted that nationally, intermediate care has about half the capacity needed to maximise its impact (NHS Benchmarking Network, 2014).

When introduced, it was expected that ICS would provide equivalent care for rehabiliation patients previously admitted to $\mathrm{CH}$ (except for a minority needing 24 hour care). However the quantitative data show that $\mathrm{CH}$ and ICS provide care for patients with different needs or at different stages on the care pathway; the majority of admissions (88\%) to $\mathrm{CH}$ were discharges from acute hospitals, whereas over $80 \%$ of patients admitted to ICS were from home. Nearly $80 \%$ of ICS patients were discharged home, compared with $54 \%$ of $\mathrm{CH}$ patients, LOS were generally shorter and death rates lower.

Results from the qualitative interviews show that both patients and staff consider $\mathrm{CH}$ and ICS to be complementary, the latter providing a lower intensity service. Both groups reported a trade off between the safety of an environment that provides 24 hour care and the convenience and comfort of being at home. The preference for rehabiliation in a community rather than acute setting is in line with other studies (Green et al., 2008; Small et al., 2009).

Staff interviews revealed some differences between managers who expressed a clear vision of the potential for home-based care, and operational staff who had more reservations about both the principle of managing patients with higher needs at home, and the practicalities of delivery, for example provision of home-based equipment. Although ANP led care was welcomed by both groups (as well as patients), this approach seemed to work better in $\mathrm{CH}$ than ICS. This is perhaps unsurprising given that most staff were used to working in a hospital environment, but demonstrates the need for the vision to be communicated as well as the need for training and clear operational procedures, such as criteria for admission to ICS. Others have noted the 'emotional labour' that staff have to undertake during service transitions (Fillmore and Le May, 2015).

As well as promoting the vision of intensive care in the community, several steps need to be taken if, as planned, ICS is to be expanded to take a higher proportion of rehabilitation patients currently managed in $\mathrm{CH}$. These include raising awareness of the service as a potential discharge destination within the acute sector, ongoing support and training for staff whose background is in a $\mathrm{CH}$ or acute setting, and ensuring the service is adequately resourced, both to provide high levels of staffing when needed, and to reduce delays in putting services and equipment in place.

\section{Strengths and limitations}

The main strength of the study is the insights it provides into the shift from $\mathrm{CH}$ to home-based care, incorporating quantitative data and the views of patients and professionals.

Quantitative elements of the evaluation were limited by the lack of routine data for patients receiving ICS, including demographic information (age, sex, ethnicity), clinical data such as diagnosis, and information about readmissions. This lack prevented examination of case mix and any meaningful economic evaluation, which would be essential to enable commissioners to make informed decisions about development of these services (Clegg et al., 2016).

Another limitation was failure to recruit a larger sampling frame of patients to be interviewed and the possibility of selection bias in those who were recruited by clinical staff, which could provide an over-favourable impression of both services. Clinical staff either did not see recruitment to research as a legitimate role for them, or did not appreciate the purpose of the study or its importance to the Trust. Finally, the failure to recruit commissioners to the qualitative study means that we lack an important perspective. 


\section{Implications for future evaluations}

Although clinical systems for GPs and community staff are useful for coordinating the care of individual patients across intermediate and primary care, there is a need for a core data set to be collected by services for routine monitoring and evaluation. Ideally this would be linked to primary care databases to enable, for example, frailty profiles to be examined (Clegg et al., 2016). Future evaluations also need to maximise engagement by clinical staff, and would benefit from a more collaborative approach than we were able to achieve, using models such as 'researcher in residence' (Marshall et al., 2014).

\section{Acknowledgements}

The authors thank the Community Trust and its staff and patients for their cooperation. The study was supported by a steering group comprising commissioners, providers and PPI representatives.

\section{Financial Support}

The study was funded by the Community Trust.

\section{Conflicts of Interest}

Simon Conroy was clinical director of the Community Trust during the study. No other authors have any conflicts.

\section{References}

Castleberry, A. 2014: NVivo 10 [software program]. Version 10. QSR International; 2012. American Journal of Pharmaceutical Education 78, 25.

Clegg, A., Bates, C., Young, J., Ryan, R., Nichols, L., Ann Teale, E., Mohammed, M.A., Parry, J. and Marshall, T. 2016: Development and validation of an electronic frailty index using routine primary care electronic health record data. Age and Ageing 45, 353-60.

Conley, J., O'Brien, C.W., Leff, B.A., Bolen, S. and Zulman, D. 2016: Alternative strategies to inpatient hospitalization for acute medical conditions: a systematic review. JAMA Internal Medicine 176, 1693-702.

Cook, P.J. and Porter, L. 1998: Community hospitals and district general hospital medical bed use by elderly people: a study of 342 general practitioner beds in Oxfordshire. Age and Ageing 27, 357-61.
Fillmore, E.H. and Le May, A. 2015: Crafting intermediate care: one team's journey towards integration and innovation. Journal of Research in Nursing 20, 56-71.

Gale, N., Heath, G., Cameron, E., Rashid, S. and Redwood, S. 2013: Using the framework method for the analysis of qualitative data in multi-disciplinary health research. $B M C$ Medical Research Methodology 13, 117.

Green, J., Forster, A., Young, J., Small, N. and Spink, J. 2008: Older people's care experience in community and general hospitals: a comparative study. Nursing Older People 20, 33-39.

Heaney, D., Black, C., O'Donnell, C., Stark, C. and Van Teijlingen, E. 2006: Community hospitals - the place of local service provision in a modernising NHS: an integrative thematic literature review. BMC Public Health 6, 309.

Marshall, M., Pagel, C., French, C., Utley, M., Allwood, D., Fulop, N., Pope, C., Banks, V. and Goldmann, A. 2014: Moving improvement research closer to practice: the Researcher-in-Residence model. BMJ Quality \& Safety 23, 801-5.

National Audit Office. 2013. Emergency admissions to hospital: managing the demand. London: HMSO.

NHS Benchmarking Network. 2013. National audit of intermediate care. Manchester: NHS Benchmarking Network.

NHS Benchmarking Network. 2014. National audit of intermediate care. Manchester: NHS Benchmarking Network.

O'Reilly, J., Lowson, K., Green, J., Young, J.B. and Forster, A. 2008: Post-acute care for older people in community hospitals - a cost-effectiveness analysis within a multi-centre randomised controlled trial. Age and Ageing 37, 513-20.

Shepperd, S., Doll, H., Angus, R.M., Clarke, M.J., Iliffe, S., Kalra, L., Ricauda, N.A., Tibaldi, V. and Wilson, A.D. 2009a: Avoiding hospital admission through provision of hospital care at home: a systematic review and meta-analysis of individual patient data. Canadian Medical Association Journal 180, 175-82.

Shepperd, S., Doll, H., Angus, R.M., Clarke, M.J., Iliffe, S., Kalra, L., Ricauda, N.A. and Wilson, A.D. 2008: Admission avoidance hospital at home. Cochrane Database of Systematic Reviews. http://www.mrw.interscience.wiley.com/cochrane/ clsysrev/articles/CD007491/frame.html.

Shepperd, S., Doll, H., Broad, J., Gladman, J., Iliffe, S., Langhorne, P., Richards, S., Martin, F. and Harris, R. 2009b: Early discharge hospital at home. Cochrane Database of Systematic Reviews. http://www.mrw.interscience. wiley.com/cochrane/clsysrev/articles/CD000356/frame.html.

Small, N., Green, J., Spink, J., Forster, A. and Young, J. 2009: Post-acute rehabilitation care for older people in community hospitals and general hospitals - philosophies of care and patients' and caregivers' reported experiences: a qualitative study. Disability and Rehabilitation 31, 1862-872.

Young, J., Green, J., Forster, A., Small, N., Lowson, K., Bogle, S., George, J., Heseltine, D., Jayasuriya, T. and Rowe, J. 2007: Postacute care for older people in community hospitals: a multicenter randomized, controlled trial. Journal of the American Geriatrics Society 55, 1995-2002.

Primary Health Care Research \& Development 2018; 19: 53-63 